\title{
Making science real: photo-sharing in biology and chemistry
}

\author{
Jenny Waycott ${ }^{\mathrm{a} *}$, Barney Dalgarno ${ }^{\mathrm{b}}$, Gregor Kennedy ${ }^{\mathrm{a}}$ and Andrea Bishop ${ }^{\mathrm{b}}$ \\ ${ }^{a}$ Health Informatics and Virtual Environments, Faculty of Medicine, Dentistry and Health \\ Sciences, The University of Melbourne, Melbourne, Australia; ${ }^{b}$ School of Education, Charles \\ Sturt University, Wagga Wagga, Australia
}

(Received 23 March 2011; final version received 19 August 2011)

In this paper, we examine students' reflections about the value of two photosharing activities that were implemented in undergraduate Biology and Chemistry subjects. Both activities aimed, broadly, to provide support for authentic and meaningful learning experiences in undergraduate science. Although the activities were similar - both required students to capture and share images as part of an independent inquiry activity - students in the Biology case study were more positive, overall, than the Chemistry students in their evaluation of the activity. In this paper, we examine the findings from the two case studies in parallel to provide insight into our understanding of meaningful learning in undergraduate science. The results suggest that, for meaningful learning to occur, the learning activity needs to be well aligned with students' individual learning goals and with the objectives and characteristics of the course. In the two case studies examined in this paper, this alignment was successful for the Biology case study but less successful in the Chemistry case study.

Keywords: science education; photo-sharing; meaningful learning

\section{Introduction}

The challenge of creating meaningful learning experiences for students is an enduring concern for higher education in general and undergraduate science in particular. Learning science typically involves developing knowledge about complex systems and sometimes difficult and abstract concepts that are at odds with the (mis)conceptions students bring to the science classroom (Laurillard 2004; Linn, Eylon, and Davis 2004). Making science accessible to students, then, is a key concern for science educators (Linn, Davis, and Eylon 2004).

We conducted evaluations of two technology-mediated learning activities that aimed, broadly, to make science learning more meaningful for students. In the first case, undergraduate Biology students took photographs of beetle specimens collected during independent fieldwork and loaded the images to a shared website. In the second case, first-year Chemistry students took photographs of everyday objects or experiences that illustrated chemistry principles in action and shared these with classmates on the Flickr website. In this paper, we examine students' reflections about the value of these activities, comparing the two cases to provide insight into our understanding of meaningful learning in undergraduate science.

*Corresponding author. Email: jwaycott@unimelb.edu.au 


\section{J. Waycott et al.}

\section{Background}

\section{Perspectives on authentic learning}

One of the prominent approaches to fostering meaningful science learning - that is, learning that is personally relevant and engaging for students - is to create authentic or "real world" learning experiences. However, authentic learning has been interpreted in a number of ways. One interpretation suggests that when learning is situated in the context in which it will ultimately be applied, students will see its relevance and importance, will be more motivated to learn and will ultimately have a better chance of transferring their knowledge outside the classroom. This is based on Brown, Collins and Duguid's (1989) concept of situated cognition and aspects of Lave and Wenger's (1991) ideas about student participation in communities of practice. Key to this interpretation is genuine participation within the community of practice, in which learners engage in the "ordinary practices of the culture" of the profession (Brown, Collins, and Duguid 1989, p. 34). However, it can be challenging to implement these kinds of authentic learning experiences in formal settings (Stein, Isaacs, and Andrews 2004). In university settings, many undergraduate subjects service students from a range of courses, creating numerous possible professional contexts and making it unfeasible to situate learning in a genuine community of practice.

A second interpretation of authentic learning focuses on the tasks themselves (as distinct from the context in which they are carried out). Herrington et al. (2004) argued that investigation activities that mirror the ill-structured and often openended nature of real-life tasks can be authentic even if not necessarily situated in a professional context. The idea of generative learning environments proposed by the Cognition and Technology Group at Vanderbilt (1990) draws on this aspect of authenticity, as does Lebow and Wager's (1994) idea of cognitive apprenticeship. In undergraduate science education, one approach might be to design tasks that involve authentic scientific inquiry; for example, conducting experiments or undertaking fieldwork to collect data for an investigation that emulates the sort of scientific inquiry conducted by researchers in that discipline. However, students who do not see themselves as ultimately becoming scientists (for example, those studying a service subject towards a professional qualification) may not be engaged by simulated research tasks.

A further interpretation takes a more learner-centred approach and relates more closely to the concept of making learning personally meaningful to students. Stein, Isaacs and Andrews (2004) argued that learning experiences may be authentic if they "engage students' lived experiences" and help them to "find meaningful connections with their current views, understandings and experiences" without necessarily being situated within a community of practice (p. 240). An alternative way to make science more meaningful and accessible to students then is to create learning activities through which students build connections between their formal knowledge and their personal experiences (Linn, Davis, and Eylon 2004; Vavoula et al. 2007). Such activities might be situated within students' "real lives" outside of university rather than within a particular professional context. In biology, for example, it is common practice to ask students to go into their everyday environments and collect biological specimens. Leonardo da Vinci's experiments where he dropped objects of various sizes and masses from the leaning tower of Pisa is an age-old example from physics, and many teachers have asked students to carry out similar experiments themselves. 
Tasks requiring students to undertake simple chemistry experiments in their kitchens at home provide another example (see, for example, Boschmann 2003).

Tasks such as these share with laboratory experiments a fundamental sequence of activities: observing, recording and analysing/interpreting. Elements of this sequence can be supported and enhanced by the use of new technologies. Mobile technologies, in particular, can be useful for capturing and recording data in inquiry activities that take place outside the classroom (Scanlon, Jones, and Waycott 2005). In recent years, mobile devices that have digital cameras embedded in them have become pervasive everyday technologies and offer the potential to enhance the data capture (or recording) aspect of scientific inquiry activities. In addition, photo- and video-sharing web tools, such as Flickr and YouTube, can be used to share the digital images students have captured. By sharing resources in this way, students can learn from their peers' experiences and see the relevance of a wide range of scientific concepts and ideas, extending the analysing/interpreting component of scientific inquiry.

This points to a further interpretation of authentic learning that draws on sociocultural perspectives (e.g., Vygotsky 1978) to emphasise the social and discursive aspects of learning. In the context of science education, undertaking collaborative scientific investigations or sharing and discussing findings can help students reach common understandings (Rule 2006). Rule argued that one of the key components of authentic learning is that "students engage in discourse and social learning in a community of learners" (p. 2). While the concept of "learning community" has been used widely, and it has been argued, problematically in recent years (see Draper 2008, for a review), it is nevertheless useful for distinguishing peer learning from the notion of communities of practice. In this paper, we refer to a learning community as a group of peers who are engaged in similar learning tasks and goals; for example, a cohort of students enrolled in a subject.

There are numerous possibilities for enhancing or extending learning communities through the use of new technologies. Photo-sharing appears to offer particular possibilities; sites such as Flickr, which enable users to "tag" photographs with keywords and connect to other users who share similar interests, have been shown to foster communication within informal learning communities (see, for example, Burgess, Foth, and Klaebe 2006; Miller and Edwards 2007). Recent research has also shown that photo-sharing can be useful in formal learning settings, as outlined below.

\section{Learning through photograph taking and sharing}

There is a growing body of work suggesting that capturing and sharing images could add value in a range of learning settings. In one example, primary school students used handheld computers with plug-in digital cameras to record images of plants while undertaking an environmental science investigation (Lai et al. 2007). In another example, university students learning about environmental issues used their own camera-enabled mobile phones to record images of local environmental blights. Students sent the photographs to a moderator who uploaded selected photographs to the project website. Participants could then review other students' photographs, which became the focus of group discussions with classmates and the moderator (Uzunboylu, Cavus, and Ercag 2009).

In other fields, learners have used camera phones to illustrate progress made on major assignments, providing visual representations that aided self-reflection and facilitated communication between lecturers and students (Cochrane and Bateman 
2009). Camera phones have also been shown to be useful for students on work placement. For instance, vocational students have used camera phones and multimedia messaging to record their progress and communicate with teachers while working on a building site (Hartnell-Young and Vetere 2005). Education students working in school settings have used mobile phones to capture artefacts such as audio recordings and digital photographs of student work (Ferry 2009). These were then shared with classmates in face-to-face discussions, providing a focal point for students' reflections on the learning experience. As these examples show, capturing and sharing images can be particularly valuable for engaging learning communities and for supporting learning that is situated outside the classroom. However, while these technologies appear to offer valuable support for learning, educators should not assume that they can be easily incorporated into all learning activities. In some cases, students may not use the tools in the way educators had intended (e.g., Petersen, Divitini, and Chabert 2008). Recent research also suggests that students may resist using personal or everyday technologies in a formal learning setting (Jones et al. 2010). Further, the examples outlined here were typically small-scale trials that highlighted the potential benefits of learning through photograph taking and sharing but provided limited empirical evidence that these activities foster meaningful learning.

In this paper, we examine findings from two case studies in which undergraduate science students captured and shared photographs to support their learning. The findings reported here are based on students' perceptions about the value of the photo-sharing activity, particularly their reflections on the relevance of the activity to their learning and the value of sharing knowledge with their peers in this way. This evaluation aims to identify lessons about the challenges and learning possibilities of introducing photo-sharing activities to create meaningful learning experiences in undergraduate science.

\section{Case studies}

The two case studies reported here were undertaken as part of a larger project, in which technology-mediated activities were implemented in eight different learning and teaching settings (see Kennedy et al. 2009). This project aimed to examine the administrative, technical and pedagogical issues that emerged when social technologies were used as learning tools in different higher education contexts. The two case studies examined in this paper share many similarities. In both cases, students used digital cameras or camera-enabled mobile phones to capture digital photographs in independent activities that took place outside the classroom. Both activities involved peer review and knowledge sharing, and both aimed to foster meaningful learning in an undergraduate science setting. However, there were also key differences. In the Biology case study (Beetle Gallery), the photo-sharing activity was used to enhance an assessable fieldwork activity (collecting beetle specimens). In the Chemistry case study (Chemistry Around Us), the photo-sharing activity was a hurdle requirement: while students were not given a graded mark, they needed to complete it to pass the course. This activity also differed from the Biology beetle collection exercise in that it did not emulate the sort of scientific inquiry that a professional scientist might undertake but was designed to encourage students to build connections between their formal learning about chemistry and their day-to-day experiences. That is, each activity represented a different interpretation of authentic learning but both aimed to facilitate knowledge-sharing to enhance meaningful learning. 


\section{Beetle Gallery}

The Beetle Gallery activity was implemented in a second-year Biology subject at Charles Sturt University, a large multicampus regional provider of both on-campus and distance education. The activity was part of a larger assignment (worth $30 \%$ of the subject mark) in which students collected and described six beetle specimens. As well as physically collecting and displaying the specimens, students photographed each beetle from at least two angles, highlighting morphological characteristics such as antennae type, leg type, thorax type, the pronotum, abdomen shape, thorax colour, wing colour and wing patterns. Students then uploaded their images, along with a document describing the beetle (and, optionally, video footage and/or audio recordings of the beetles) to an online Beetle Gallery, a file sharing site hosted on the University's Learning Management System (LMS). Students created a new folder for each beetle specimen they uploaded, using a unique descriptor to label each beetle folder, including the antennae, leg and thorax type. Students were also required to compare and contrast their beetles to other specimens in the Beetle Gallery. Students' contributions to the Beetle Gallery were worth $20 \%$ of the mark for the overall assignment.

Initially, 44 students were enrolled in this subject (25 on-campus and 19 distance education students), and they all participated in the Beetle Gallery exercise. However, two on-campus students did not complete the unit and did not submit the final assessment item.

\section{Chemistry Around Us}

For this case study, first-year Chemistry students at The University of Melbourne, a large metropolitan university, used digital cameras to capture chemistry-related images from everyday life that they then published and shared with other students on the Flickr website. Students were given two topics each (from nine topics covered in lectures) and asked to take photographs, drawing on their everyday experiences that illustrated those topics. Students were asked to publish at least two photographs on Flickr (to a private group, set up by the project team) and to write textbook-style captions that outlined how their images illustrated that topic. Students also reviewed other students' photographs and captions and nominated the two best photographs for a specific topic. While students uploaded and viewed the photographs in Flickr, they "voted" for the best images on the University's LMS.

This activity was introduced for the first time in this implementation and was one of four independent learning tasks in this subject. During this case study, there were 920 students enrolled in first-year Chemistry; 799 students completed the task. At the end of semester, 1894 photographs had been published and almost all photographs $(97.6 \%)$ were accompanied by a text description (see Waycott and Kennedy 2009, for more information about this case study).

\section{Method}

In both case studies, students were asked to complete an evaluation questionnaire that was used in each of the eight case studies for the project (see Gray et al. 2009). The overall questionnaire was designed to address the aims of the larger study; for the purposes of this paper, we have chosen to focus on those items that can give us 


\section{J. Waycott et al.}

some insight into whether students found the activity to be meaningful or personally relevant to their learning. The survey asked students to indicate whether they felt the activity had helped them in their studies this semester ("yes," "no" or "maybe") and to rate, on a seven-point scale, how relevant, interesting, useful and enjoyable they felt the activity was. In addition, five-point Likert scales were used to gauge levels of agreement in response to several statements regarding how well the activity supported various aspects of students' learning (e.g., "[This activity] helped me better understand the material I was studying").

Qualitative data were elicited through open-ended questions asking students to indicate, for example, the best and worst things about the activity, how they felt it could have been improved, and to elaborate on why they felt the activity did/did not support their learning. We also held focus group discussions and interviews with students at the end of the semester, eliciting more information about students' perceptions of the photo-sharing activities. For the purposes of this paper, we have examined the qualitative data to identify key themes that provide an indication of students' views on the relevance and usefulness of the activity.

In the Biology case study, 19 on-campus and four distance students completed the survey $(55 \%$ response rate). A further four on-campus students participated in a focus group discussion and four distance students were interviewed individually by telephone. In the Chemistry case study, the response rate to the online questionnaire was very low, with only 44 students completing the voluntary survey (in addition, some respondents did not complete all the questions). The low response rate highlights the need to interpret the quantitative data, in particular, with caution. However, given that, in this descriptive analysis, limited inferential statistics will be used, we feel it is appropriate to include these data. Ten Chemistry students participated in a focus group discussion.

\section{Results}

\section{Students' evaluation of the learning value of the activity}

When asked "Did this activity help you in your studies this semester?," most of the Biology students who completed the survey responded positively (17 students, or $74 \%$, said "yes" while 3 students, or 13\%, said "no"). In contrast, most of the Chemistry students who took part in the evaluation said the activity did not help them in their studies (24 students, or 67\%, said "no"). A similar pattern can be seen in the levels of agreement/disagreement to statements describing the potential learning benefits of the activity (Table 1). Overall, students in the Biology case study felt the activity supported their learning. In contrast, most Chemistry respondents disagreed with many of the learning benefit statements. There were slightly more favourable responses from Chemistry students to the statements "the activity improved my ability to share my knowledge and/or opinions with other students" (10 students, or 26\% of respondents, agreed/strongly agreed) and it "helped me develop my thinking skills by writing or producing study related material" (10 students, or $26 \%$, agreed/strongly agreed). Overall, however, most Chemistry respondents disagreed with the statements proposing the activity supported their learning. As shown in Table 2, a $t$-test comparing the mean response on each item relating to the way the photo-sharing activity supported learning indicates that Biology students were significantly stronger in their agreement on all items. 
Table 1. Degree of agreement with statements about how the photo-sharing activity supported learning.*

\begin{tabular}{|c|c|c|c|c|c|c|c|c|c|c|}
\hline \multirow[b]{2}{*}{ The photo-sharing activity ... } & \multicolumn{5}{|c|}{ Biology $(\mathrm{N}=23)$} & \multicolumn{5}{|c|}{ Chemistry $(\mathrm{N}=38)$} \\
\hline & $\begin{array}{l}\text { Strongly } \\
\text { agree }\end{array}$ & Agree & Neutral & Disagree & $\begin{array}{l}\text { Strongly } \\
\text { disagree }\end{array}$ & $\begin{array}{l}\text { Strongly } \\
\text { agree }\end{array}$ & Agree & Neutral & Disagree & $\begin{array}{l}\text { Strongly } \\
\text { disagree }\end{array}$ \\
\hline $\begin{array}{l}\text { Helped me better understand the material I } \\
\text { was studying }\end{array}$ & 3 & 13 & 6 & 1 & 0 & 1 & 3 & 8 & 11 & 15 \\
\hline $\begin{array}{l}\text { Improved my ability to reflect on what I was } \\
\text { learning }\end{array}$ & 3 & 12 & 6 & 1 & 1 & 1 & 6 & 7 & 12 & 11 \\
\hline $\begin{array}{l}\text { Improved my ability to share my knowledge } \\
\text { and/or opinions with other students }\end{array}$ & 5 & 12 & 4 & 2 & 0 & 2 & 8 & 8 & 14 & 6 \\
\hline $\begin{array}{l}\text { Helped me develop my thinking skills by } \\
\text { writing or producing study-related material }\end{array}$ & 3 & 12 & 7 & 1 & 0 & 2 & 8 & 9 & 10 & 9 \\
\hline $\begin{array}{l}\text { Helped me develop my independent research } \\
\text { skills }\end{array}$ & 2 & 12 & 7 & 0 & 1 & 1 & 6 & 11 & 10 & 9 \\
\hline
\end{tabular}

*Figures show the number of students who gave each response. Some survey respondents skipped these questions. 


\section{J. Waycott et al.}

Table 2. Comparisons between Biology and Chemistry students in degree of agreement with statements about how the photo-sharing activity supported learning (where $1=$ "strongly agree" and $5=$ "strongly disagree").

\begin{tabular}{|c|c|c|c|c|c|c|}
\hline \multirow[b]{2}{*}{ The photo-sharing activity ... } & \multicolumn{2}{|c|}{ Biology } & \multicolumn{2}{|c|}{ Chemistry } & \multirow[b]{2}{*}{$t$} & \multirow[b]{2}{*}{$p$} \\
\hline & Mean & $\begin{array}{l}\text { Standard } \\
\text { deviation }\end{array}$ & Mean & $\begin{array}{l}\text { Standard } \\
\text { deviation }\end{array}$ & & \\
\hline $\begin{array}{l}\text { Helped me better understand the } \\
\text { material I was studying }\end{array}$ & 2.2 & 0.7 & 4.0 & 1.1 & 6.73 & $<0.001$ \\
\hline $\begin{array}{l}\text { Improved my ability to reflect on } \\
\text { what I was learning }\end{array}$ & 2.4 & 0.9 & 3.7 & 1.2 & 4.75 & $<0.001$ \\
\hline $\begin{array}{l}\text { Improved my ability to share my } \\
\text { knowledge and/or opinions with } \\
\text { other students }\end{array}$ & 2.1 & 0.9 & 3.4 & 1.1 & 4.45 & $<0.001$ \\
\hline $\begin{array}{l}\text { Helped me develop my thinking } \\
\text { skills by writing or producing } \\
\text { study-related material }\end{array}$ & 2.3 & 0.8 & 3.4 & 1.2 & 4.10 & $<0.001$ \\
\hline $\begin{array}{l}\text { Helped me develop my independent } \\
\text { research skills }\end{array}$ & 2.4 & 0.8 & 3.5 & 1.1 & 4.40 & $<0.001$ \\
\hline
\end{tabular}

\section{Students' general perceptions of the activity}

In order to establish students' broad perceptions of the learning tasks, we asked them to provide ratings of several single-word descriptors (e.g., "interesting" and "useful"), using a 7-point scale (1="not at all"; 7 ="extremely"). Overall, the students in the Biology case study gave higher ratings to positive items ("interesting," "easy to use," "useful" and "enjoyable") than they did to negative items ("irrelevant" and "boring"). In contrast, the mean ratings from the Chemistry students who responded to the survey were generally lower for the positive items and higher for the negative items (see Figure 1). As shown in Table 3, a $t$-test comparing the mean response on each item indicates that Biology students were significantly stronger in their agreement on the four positive items (interesting, easy to use, useful and

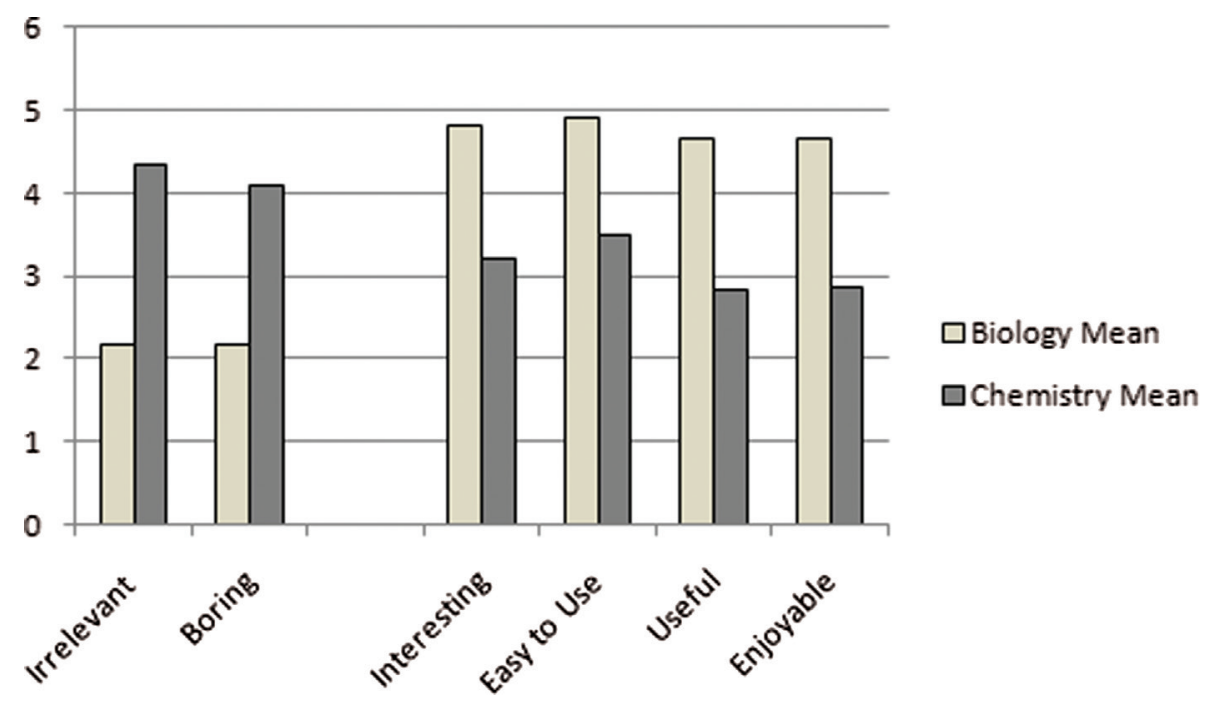

Figure 1. Biology and Chemistry students' mean ratings of the learning task. 
Table 3. Comparisons between Biology and Chemistry students in degree of agreement with single word descriptors of the activity (where $1=$ "not at all" and 7 ="extremely").

\begin{tabular}{|c|c|c|c|c|c|c|}
\hline & \multicolumn{2}{|r|}{ Biology } & \multicolumn{2}{|r|}{ Chemistry } & \multirow[b]{2}{*}{$t$} & \multirow[b]{2}{*}{ p } \\
\hline & Mean & Standard deviation & Mean & Standard deviation & & \\
\hline Interesting & 4.8 & 1.8 & 3.2 & 1.7 & -3.56 & 0.001 \\
\hline Easy to use & 4.9 & 1.6 & 3.5 & 1.8 & -3.12 & 0.003 \\
\hline Useful & 4.7 & 1.6 & 2.8 & 1.6 & -4.35 & $<0.001$ \\
\hline Enjoyable & 4.7 & 1.3 & 2.9 & 1.7 & -4.3 & $<0.001$ \\
\hline Boring & 2.2 & 1.4 & 4.1 & 2.0 & 4.1 & $<0.001$ \\
\hline Irrelevant & 2.2 & 1.6 & 4.4 & 2.2 & 4.2 & $<0.001$ \\
\hline
\end{tabular}

enjoyable) and Chemistry students were significantly stronger in their agreement on the two negative items (boring and irrelevant).

The qualitative data, elicited from survey responses and interview and focus group discussions, provide further information about these differences. A number of themes about learning and engagement emerged in the Biology case study; these were not limited to the online aspect of the exercise. Indeed, students frequently noted that the "best aspect" of the exercise was that they were required to physically collect beetles from their habitats, although some students also expressed frustration at the time and effort involved in sourcing beetles. One student described collecting and handling specimens as "opening your eyes to a lot of things that we might have covered in the text already but until you see a [beetle] under a microscope, it doesn't stick in your memory nearly as much." Another noted: "on a page in a book [the beetle] looks quite defined ... but actually looking at live specimens it is totally different." Many students indicated that they would like to see this kind of activity used in other areas of their studies. However, as one student clarified, this would only be considered valuable "if it was beneficial to the study [and] not [just] for the sake of it."

In contrast, Chemistry students' responses to the open-ended survey items were often negative, with comments such as: "It didn't really aid any understanding of the course" and "I learnt about one little topic, not all the others." A number of students clearly felt the task lacked relevance and interfered with other higher priority tasks, such as preparing for examinations. For example:

I unfortunately failed to see the point [of this activity]. After discussing it with other students, I found that they thought similarly of the exercise. It seems an unnecessary and unhelpful hurdle that will not actually teach us anything practical.

I thought I could have used my time more effectively, for example, I could've been revising the examinable material rather than mucking around trying to upload some photos.

These students did not see the photo-sharing activity as relevant to their learning needs and goals in first-year Chemistry. Similarly, when asked what they believed the purpose of the activity was, a small number of students appeared to not understand that the primary aim of the activity was to encourage them to think about the role chemistry plays in everyday life. Instead, they suggested that the purpose of the activity was to "make us use technology" or to take photographs. Some students expressed exasperation at having to undertake a task that they felt was not relevant to this subject: "I signed up for chemistry, not photography!!!" 


\section{J. Waycott et al.}

The students who took part in the focus group, however, were generally more positive in their reflections. They noted that the activity successfully enabled them to link their formal learning about chemistry to the "real world" around them. For instance, "it was good to actually put it [chemistry] into reality" and "I think learning by analogy is very, very helpful. So if you go out there and find an example of something ... you're always going to be able to refer to that later." The focus group session also included some discussion about the value of using mobile technologies to capture and share images. These students "liked the fact you could [do the activity] from anywhere." One student related how she had taken a photograph while out hiking, and another said she had taken one of her photographs while on the train. In these cases, students were using technologies that they carried about with them, making it easier to incorporate this learning activity into their everyday life.

\section{Students' perceptions of the knowledge sharing component of the activity}

As shown in Table 1, 17 Biology students who responded to the survey felt the activity improved their ability to share knowledge or opinions with other students $(74 \%$ of respondents). This positive response was also reflected in a number of student comments from the qualitative data. The knowledge-sharing aspect appeared to be particularly beneficial because the cohort was geographically dispersed. One student noted: "I think it's amazing that we're all over the state, we're all over the country and we can all look at the different beetles that we've selected. That's amazing to me."

Many Biology students, both on-campus and distance, commented that the photo-sharing aspect of the task made them feel connected to the group, which appeared to improve engagement with the activity: "It made me feel involved in the subject ... like I was part of a group. I guess for me that was the main thing."

In the Chemistry case study, we did not find strong evidence that students felt more connected to the learning community by taking part in this activity. However, there were Chemistry students who found it useful to share knowledge and review other students' photographs. When asked to indicate the best thing about the activity, typical comments included: "There were some good photos in my review topic, and some explanations that were clear and concise on the topic and helped me to understand the concept" and "[It was] interesting to see what other people thought."

Similarly, in the Biology case study, students said they found the photo-sharing aspect of the exercise beneficial for their learning. They liked having the opportunity to self-assess and evaluate their progress by comparing and contrasting their work to other students' work (e.g., "[It] helps being able to plot where you're at"). In addition, the photo-sharing activity exposed Biology students to a broader range of beetle specimens and possible interpretations:

Going through everyone's photos and saying 'well that's the same as my beetle but I've actually labelled it differently'... it was interesting to see how different people interpreted those slight differences in those characteristics.

Having the opportunity to view a number of different beetles and their features gave a broader overview than if I had just focused on my own, some of which were quite similar.

Students in the Chemistry focus group also noted this benefit: "it's interesting to see other students' perspectives on your topic .... You sort of looked at it and you're 
like 'oh, so that's what they thought' whereas I might have thought something completely different."

However, a number of students in the Chemistry case study felt there was limited value in having access to and viewing other students' work. Students noted that, in some cases, their peers appeared to misunderstand the instructions and made errors in their captions: "there were wrong/misleading descriptions of a concept." In addition, students raised concerns about the quality of images they were asked to review. For example: "they're usually non-professional photos and can be dull" and "a lot of [the photos] are very blurry .... You can't see what they're taking a photo of".

The repetition of photographs and the volume of pictures produced by such a large cohort also made the peer review component of the activity challenging (e.g., "everyone ended up doing similar pictures"). Perceptions about the quality of student-created material and the repetition in images led a number of students to question the value of reviewing other students' work and the usefulness of a collaborative photo-sharing activity as a whole.

\section{Discussion}

The two photo-sharing activities in these case studies both aimed, broadly, to provide support for authentic and meaningful learning experiences in undergraduate science. The two activities appeared, in many ways, to be quite similar: both involved, for instance, capturing and sharing photographs as part of an independent inquiry activity in undergraduate science. However, analysing the two case studies in parallel has revealed strong differences in the way students responded to the photo-sharing tasks in each setting. Overall, the Biology students who participated in the evaluation were more positive and rated the activity more highly than did the Chemistry participants. Most of the Chemistry students who responded to the survey did not see the activity as relevant and meaningful for their learning.

These results question our understanding of "meaningful learning" in undergraduate science, suggesting that the authenticity of the task is central to meaningful learning. The Biology case study provided an example of a more authentic learning activity: the photo-sharing task contributed to a fieldwork activity that emulated the sort of task a professional biologist might undertake. Students in this case study had no difficulty in recognising the value of the activity for their learning. In contrast, many of the Chemistry students who responded to the survey questioned the relevance of the activity, sometimes expressing exasperation that they were being asked to spend time on an activity that they felt was "pointless."

However, it appears that numerous features of the learning setting and the activity design may have contributed to Chemistry students' negative evaluations of this activity, particularly how well the task aligned with individual students' strategic approaches to learning and studying. Despite the learning task having a clear and considered educational rationale - that is, to encourage students to consider how chemistry principles are embedded in everyday experiences - students did not see the activity as well aligned with their own, individual learning needs and goals. It seems that many students had clear views of the most important components of the firstyear Chemistry curriculum and the most appropriate activities that needed to be completed; and, for many students, the photo-sharing activity was not one of them. The fact that the activity was not assessed but was a hurdle requirement would have contributed to students' perceptions about the relative importance of the different 
activities included in the curriculum. Preparing and revising for an examination was considered important; taking photographs of chemistry principles in action was not. In contrast, the Biology case study was part of a larger assessment activity. The fieldwork task of collecting and describing beetles had a clear place in the curriculum. The photo-sharing task extended this activity, making it possible for students to share their fieldwork experiences. It appears, then, that learning activities that are aligned with the course curriculum and assessment - in line with Biggs' (1996) notion of constructive alignment - may be viewed more favourably as relevant and meaningful for students.

Furthermore, knowledge-sharing appeared to have particular benefits for students in the Biology case study because of the features of the setting in which this activity took place. First, some of the students were studying off-campus and found that being able to share and view other students' work in this way made them feel more connected to the learning community. Second, it was useful for students to be able to see other students' beetle specimens to extend their learning. Normally, in a fieldwork exercise such as this, students would only be exposed to the samples they had been able to source and observe. The photo-sharing task meant students could learn from a larger and more varied data set. Third, this was a smaller group of students than in the first-year Chemistry setting. Chemistry students complained about the repetition of photographs, the quality of images and the volume of photographs that they needed to look at in order to complete the peer review component of the task. It appears that introducing photo-sharing in a large cohort such as this will not necessarily create opportunities for meaningful learning through knowledge-sharing. In contrast, students may find reviewing large volumes of student-created content to be a difficult and disengaging task.

\section{Conclusion}

Fostering meaningful learning in undergraduate science is a complex endeavour. Designing authentic learning tasks, encouraging students to build connections between their formal learning and everyday experiences and facilitating knowledge-sharing within learning communities may help individual students in certain settings become more engaged as learners. However, these approaches may not be successful with all students in all contexts. For meaningful learning to occur, the task needs to align well with students' individual learning goals and with the objectives and characteristics of the course. In designing authentic tasks for university students, alignment with the subject goals and the likely learning and achievement goals of the student may be more important than personal meaningfulness. Moreover, the fostering of a learning community will only work if students have a personal reason for engaging with the task and if features of the learning community (e.g., its size) are conducive to knowledge-sharing and peer learning. Photo-sharing in science may be a useful way of fostering knowledge-sharing and enriching the learning experience, but its relevance as a learning activity is dependent on the context in which it is used and how it contributes to the other learning activities students are engaged in.

\section{Acknowledgements}

We would like to thank the students and staff who participated in these case studies, especially the lecturers in the Department of Chemistry at the University of Melbourne and the School of Environmental Sciences at Charles Sturt University who implemented the case study activities. 
Particular acknowledgements are due to Peter Tregloan, Carmel Abraham, Rosemary Chang and Andrea Wilson.

These studies were undertaken as part of the Educating the Net Generation project, conducted in collaboration with Sue Bennett, Rosemary Chang, Kathleen Gray, Terry Judd, Kerri-Lee Krause and Karl Maton. Support for this project was provided by the Australian Learning and Teaching Council, Ltd, an initiative of the Australian Government Department of Education, Employment and Workplace Relations. The views expressed in this paper do not necessarily reflect the views of the Australian Learning and Teaching Council.

\section{References}

Biggs, J. (1996) 'Enhancing teaching through constructive alignment', Higher Education, vol. 32 , pp. 347-364.

Boschmann, E. (2003) 'Teaching chemistry via distance education', Journal of Chemical Education, vol. 80, pp. 704-708.

Brown, J. S., Collins, A. \& Duguid, P. (1989) 'Situated cognition and the culture of learning', Educational Researcher, vol. 18, pp. 32-42.

Burgess, J., Foth, M. \& Klaebe, H. (2006) 'Everyday creativity as civic engagement: a cultural citizenship view of new media', Proceedings of Communications Policy \& Research Forum, Sydney, [online] Available at: http://eprints.qut.edu.au/ (accessed 27 June 2009).

Cochrane, T. \& Bateman, R. (2009) 'Smartphones give you wings: pedagogical affordances of mobile Web 2.0', in Same places, Different Spaces. Proceedings of the Australasian Society for Computers in Learning in Tertiary Education 2009, eds. R. Atkinson and C. McBeath, Ascilite, Auckland, pp. 142-152.

Cognition and Technology Group at Vanderbilt. (1990) 'Technology and the design of generative learning environments', Educational Technology, vol.31, pp. 34-40.

Draper, S. W. (2008) 'Learning and Community', in Learners in the Co-Creation of Knowledge: Proceedings of the LICK 2008 Symposium, Edinburgh 30 October 2008, eds A. Comrie et al., Napier Universitypp, Edinburgh, pp. 132-144.

Ferry, B. (2009) 'Using mobile phones to enhance teacher learning in environmental education', in New Technologies, New Pedagogies: Mobile Learning in Higher Education, eds J. Herrington et al., University of Wollongong, Wollongong, pp. 45-55.

Gray, K. et al. (2009) Educating the Net Generation: A Toolkit of resources for Educators in Australian Universities, Australian Learning and Teaching Council, Strawberry Hills, NSW.

Hartnell-Young, E. \& Vetere, F. (2005) 'Lifeblog: a new concept in mobile learning?' Proceedings of the 2005 IEEE International Workshop on Wireless and Mobile Technologies in Education, IEEE, Los Alamitos, CA, pp. 174-178.

Herrington, J. et al. (2004) 'Designing authentic activities in web-based courses', Journal of Computing in Higher Education, vol. 16, pp. 3-29.

Jones, N. et al. (2010) 'Get out of MySpace!', Computers \& Education, vol. 54, pp. 776-782.

Kennedy, G. et al. (2009) Educating the Net Generation Handbook: A Handbook of Findings for Practice and Policy, Australian Learning and Teaching Council, Strawberry Hills, NSW.

Lai, C.-H. et al. (2007) 'Affordances of mobile technologies for experiential learning: the interplay of technology and pedagogical practices', Journal of Computer Assisted Learning, vol. 23 , pp. $326-337$.

Laurillard, D. (2004) 'Rethinking the teaching of science', in Mediating Science Learning Through Information and Communications Technology, eds R. Holliman \& E. Scanlon, Routledge Falmer, London and New York, pp. 27-50.

Lave, J. \& Wenger, E. (1991) Situated Learning: Legitimate Peripheral Participation, Cambridge University Press, Cambridge, England.

Lebow, D. G. \& Wager, W. W. (1994) 'Authentic activity as a model for appropriate learning activity: implications for design of computer-based simulations', Proceedings of Selected Research and Development Presentations, 1994 National Convention of the Association for Educational Communications and Technology, Nashville, TN.

Linn, M. C., Davis, E. A. \& Eylon, B.-S. (2004) 'The scaffolded knowledge integration framework for instruction', in Internet Environments for Science Education, eds M. C. Linn, E. A. Davis \& P. Bell, Lawrence Erlbaum Associates, Mahwah, NJ, pp. 47-72. 


\section{J. Waycott et al.}

Linn, M. C., Eylon, B.-S. \& Davis, E. A. (2004) 'The knowledge integration perspective on learning', in Internet Environments for Science Education, eds M. C. Linn, E. A. Davis \& P. Bell, Lawrence Erlbaum Associates, Mahwah, NJ, pp. 29-46.

Miller, A. D. \& Edwards, W. K. (2007) 'Give and take: a study of consumer photo-sharing culture and practice' Proceedings of the SIGCHI Conference on Human Factors in Computing Systems, eds. B. Begole et al., ACM Press, New York, pp. 347-356.

Petersen, S. A., Divitini, M. \& Chabert, G. (2008) 'Identity, sense of community and connectedness in a community of mobile language learners', ReCALL, vol. 20, pp. 361-379.

Rule, A. C. (2006) 'The components of authentic learning', Journal of Authentic Learning, vol. 3 , pp. $1-10$.

Scanlon, E., Jones, A. \& Waycott, J. (2005) 'Mobile technologies: prospects for their use in learning in informal science settings', Journal of Interactive Media in Education, vol. 25, pp. $1-17$.

Stein, S. J., Issacs, G. \& Andrews, T. (2004) 'Incorporating authentic learning experiences within a university course', Studies in Higher Education, vol. 29, pp. 239-258.

Uzunboylu, H., Cavus, N. \& Ercag, E. (2009) 'Using mobile learning to increase environmental awareness', Computers \& Education, vol. 52, pp. 381-389.

Vavoula, G., et al. (2007) 'Learning Bridges: a role for mobile technologies in education', Educational Technology, vol. XLVII, pp. 33-36.

Vygotsky, L. S. (1978) Mind in Society: The Development of Higher Psychological Processes, Translation M. Cole, et al., Harvard University Press, Cambridge, MA and London.

Waycott, J. \& Kennedy, G. (2009) 'Mobile and Web 2.0 technologies in undergraduate science: situating learning in everyday experience' in Same Places, Different Spaces. Proceedings of the Australasian Society for Computers in Learning in Tertiary Education 2009, eds. R. Atkinson and C. McBeath, Ascilite, Auckland, pp. 1085-1095. 